\title{
MODEL KEBERHASILAN DAN KEBERLANGSUNGAN KINERJA TERBAIK (MK3T) SISTEM INFORMASI STUDI KASUS: SISTEM INFORMASI E-AUDIT DI BADAN PEMERIKSA KEUANGAN RI
}

\author{
Nurochman', Yoanes Bandung ${ }^{1}$, John Welly ${ }^{2}$ \\ ${ }^{1}$ Sekolah Teknik Elektro dan Informatika (STEI), Institut Teknologi Bandung, Jl. Ganesha 10 Bandung \\ ${ }^{2}$ Sekolah Bisnis dan Manjemen (SBM), Institut Teknologi Bandung, Jl. Ganesha 10 Bandung
}

Email: nurochman81@gmail.com

\begin{abstract}
Abstrak
Badan Pemeriksa Keuangan Republik Indonesia (BPK RI) mengembangkan sistem informasi (SI) $e$-audit dengan strategi me-link and match-kan $e$-BPK dan $e$-auditee. SI $e$ audit mendorong pelaksanaan pemeriksaan laporan pertanggungjawaban keuangan negara dilakukan secara lebih efektif dan efisien. Namun, data statistik menunjukkan bahwa lebih dari $70 \%$ program perubahan yang sifatnya second order mengalami kegagalan. Kegagalan tersebut terjadi akibat besarnya resistansi dari berbagai pihak yang terdampak oleh perubahan tersebut. Tujuan penelitian ini untuk mengembangkan Model Keberhasilan dan Keberlangsungan Kinerja Terbaik (MK3T) Sistem Informasi. Model ini diperlukan untuk menjamin bahwa SI yang dibangun BPK RI akan berjalan dan mempunyai kinerja optimal dalam jangka panjang. Model tersebut dikembangkan berdasar kombinasi antara model organization health index $(\mathrm{OHI})$ dan model DICE. Penelitian dilakukan dengan metode campuran, diawali dengan penyebaran kuesioner. Responden dipilih dengan metode purposive sampling, yaitu para pemeriksa di BPK RI. 100 sampel memenuhi syarat untuk dilakukan pengolahan data statistik dengan metode Structural Equation Modelling (SEM) SmartPLS versi 2.0. Lima elemen yang berpengaruh signifikan terhadap keberhasilan dan keberlangsungan kinerja SI e-audit, yaitu: leadership, culture \& climate, capabilities, motivation, innovation \& learning. Nilai $t$-statistik lima elemen tersebut adalah 2,$38 ; 2,00$; 2,$36 ; 2,22 ; 3,10$. Nilai tersebut lebih besar dari nilai $t$-tabel dengan tingkat signifikansi $95 \%$ $(\alpha: 0,05=1,96)$ yang merupakan batas nilai pengaruh sebuah variabel untuk dinyatakan berpengaruh signifikan.
\end{abstract}

Kata Kunci : sistem informasi, e-audit, keberhasilan, keberlangsungan, kinerja

\begin{abstract}
The Audit Board of the Republic of Indonesia (BPK RI) developed e-audit information systems (IS) with strategy to link and match e-BPK and e-Auditee. Its encourage the process of audit of government's financial report carried out more effectively and efficiently. However, statistics show that more than $70 \%$ of second order changes was failed. The failure occurred due to the high resistance of the various parties affected by such changes. The purpose of this study is to develop a Success and Sustainability Top Performance Model (MK3T) of Information Systems. This model is necessary to ensure that the IS will run and have optimal performance for a long time. The model was developed based on the combination of organization health index (OHI) model and DICE models. The study was conducted with a mix-methods, starting with the distribution of questionnaires. Respondents were selected by purposive sampling method, i.e. auditors in the BPK RI. 100 samples eligible for statistical data processing performed by the method of Structural Equation Modeling (SEM) SmartPLS version 2.0. Five elements that significantly influence the success and sustainability of e-audit information system, namely: leadership, culture and climate, capabilities, motivation, innovation and learning. T-statistic scores of the five elements is $2.38 ; 2.00 ; 2.36 ; 2.22 ; 3.10$. It is greater than the value of $t$ table with a significance level of $95 \%(\alpha: 0.05=1.96)$ which is the limit value for the effect of a variable to declared significant.
\end{abstract}

Keywords: information systems, e-audit, success, sustainability, performance 


\section{Pendahuluan}

Perkembangan sistem informasi (SI) membawa dampak yang besar terhadap kehidupan masyarakat, bangsa, serta negara. Tidak terkecuali perkembangan SI tersebut juga berdampak pada strategi dan metode pengelolaan keuangan negara. Namun demikian, masyarakat menilai kinerja pengelolaan keuangan negara tidak semakin membaik paska reformasi, namun justru semakin menurun [1]. Semakin menurunnya kepercayaan masyarakat tersebut menjadi tantangan bagi BPK RI untuk mengambil peran strategis dalam mewujudkan tata kelola dan tanggungjawab keuangan negara yang transparan dan akuntabel. Menyadari hal tersebut BPK RI mengembangkan sistem informasi $e$-audit dengan strategi me-link and match-kan $e$-BPK dan e-auditee. Implementasi sistem informasi $e$-audit akan mendorong pelaksanaan pemeriksaan laporan pengelolaan dan tanggung jawab keuangan negara dilakukan secara lebih efektif dan efisien [2]. Perubahan yang dilakukan BPK RI tersebut tidak hanya berpengaruh terhadap infrastruktur dan sarana/prasarana. Lebih jauh dari itu, perubahan tersebut dapat digolongkan dalam perubahan yang sifatnya second order karena akan berdampak pada strategi, iklim, perilaku, serta budaya organisasi [3]. Namun demikian, data statistik menunjukkan bahwa lebih dari $70 \%$ perubahan yang sifatnya second order mengalami kegagalan [4].

Organisasi memanfaatkan sistem informasi/teknologi informasi (information system/IS) dengan tujuan untuk pemrosesan data (data processing/DP), sistem informasi manajemen (management information system/MIS), atau sistem informasi strategis (strategic information system/SIS) [5]. DP berarti pemanfaatan sistem informasi bertujuan untuk meningkatkan efisiensi operasional organisasi dengan otomatisasi proses pengolahan informasi, MIS memanfaatkan sistem informasi untuk meningkatkan efektivitas manajemen dengan menyediakan informasi handal yang diperlukan untuk pengambilan keputusan, sedangkan SIS berarti sistem informasi bermanfaat untuk membangun keuntungan kompetitif [5]. Organisasi akan mencapai tujuan-tujuan tersebut jika IS dapat mendorong optimalnya kinerja organisasi baik dalam jangka pendek maupun jangka panjang. IS yang memberikan keuntungan kompetitif jangka pendek saja, hanya akan memberikan manfaat sementara dan justru bernilai negatif jika dibandingkan dengan cepatnya respon para pesaingnya [6]. Dukungan IS untuk kinerja organisasi dalam jangka panjang dapat diwujudkan jika IS dapat berjalan terus, tidak hanya berhenti sampai tahap implementasi saja [7]. Keberlangsungan IS dapat dicapai jika sistem tersebut siap untuk dioperasikan dan digunakan untuk seluruh siklus organisasi [8]. Kegagalan suatu organisasi untuk mempertahankan perubahan melewati tahap implementasi, lebih dari $70 \%$ diantaranya disebabkan oleh faktor yang berhubungan dengan kesehatan organisasi, yaitu resistansi dan perilaku manajemen yang tidak mendukung [4].

Banyak penelitian yang telah dilakukan sebelumnya terkait dengan keberlangsungan sistem informasi. Zhang menyatakan bahwa keberlangsungan sistem informasi dipengaruhi oleh faktor internal organisasi yang meliputi keberlangsungan kepemimpinan dan koordinasi diantara para karyawan [9]. Penelitian lain juga menyatakan bahwa implementasi IS dipengaruhi oleh faktor internal organisasi lainnya yaitu: keragaman pola koordinasi dan kerjasama, pembagian tanggungjawab, serta komitmen anggota organisasi terhadap implementasi IS [10]; [11]. Keterbatasan berbagai penelitian tersebut adalah dilakukan pada organisasi privat, sehingga akan berbeda jika diterapkan pada organisasi publik. Menyadari hal tersebut Nurdin melakukan penelitian tentang pengaruh faktor internal organisasi terhadap keberlangsungan implementasi IS pada organisasi pemerintahan [12]. Namun penelitian ini hanya fokus pada faktor internal, yaitu: koordinasi, kerjasama, distribusi tanggungjawab, serta komitmen anggota organisasi, sehingga tidak memasukkan faktor budaya, iklim organisasi dan kapabilitas organisasi.

Berangkat dari beberapa keterbatasan tersebut, peneliti mencoba memperluas penelitian tentang keberlangsungan sistem informasi. Penelitian ini bertujuan untuk mengembangkan Model Keberhasilan dan Keberlangsungan Kinerja Terbaik (MK3T) Sistem Informasi. Penemuan model tersebut akan memberikan saran yang kontekstual bagi BPK RI dalam upaya mengoptimalkan kinerja pemeriksaan pengelolaan dan tanggung jawab keuangan negara. Penelitian ini akan menjawab rumusan masalah, yaitu: bagaimana mengembangkan model yang akan menjamin sistem informasi e-audit dapat berjalan dan mempunyai kinerja optimal dalam jangka waktu yang panjang, sehingga pengelolaan keuangan negara yang transparan dan akuntabel akan tercapai. Penelitian ini didasarkan pada beberapa teori tentang kinerja, kinerja terbaik, kesehatan organisasi, keberlangsungan kinerja sistem informasi, serta DICE framework.

Kinerja adalah sesuatu yang diberikan perusahaan kepada para pemangku kepentingan meliputi aspek keuangan dan kinerja operasional. 
Kinerja tersebut diukur dengan keuntungan bersih, return on investment, biaya operasi bersih, serta perputaran saham [4]. Turban juga menekankan bahwa tingkat kinerja tidak saja bergantung pada apa yang dikerjakan organisasi, namun juga ditentukan oleh lingkungan bisnis [13]. Wheelen dan Hunger mengartikan bahwa kinerja adalah hasil akhir dari sebuah aktivitas termasuk keluaran dari sebuah proses manajemen strategis, dimana praktek manajemen strategis digunakan untuk menyatakan kemampuan untuk meningkatkan kinerja organisasi [14]. Sementara Armstrong mendefinisikan kinerja sebagai sebuah proses fleksibel dan terus-menerus yang melibatkan manajer dan para partnernya untuk melakukan kegiatan. Pelaksanaan kegiatan tersebut dibingkai dengan seperangkat kerangka kerja yang mengatur bagaimana mereka bekerja sama untuk mencapai hasil yang telah ditetapkan [15]. Berdasar berbagai definisi tentang kinerja organisasi tersebut dapat disimpulkan bahwa setiap organisasi mempunyai fleksibilitas untuk membangun definisi dan parameter pengukuran kinerjanya. Hal ini terkait dengan visi, misi serta lini bisnis yang dibidangi. Namun secara umum dapat ditarik kesimpulan bahwa kinerja organisasi merupakan hasil dari sebuah proses bisnis yang terukur (measurable). Pengukuran tersebut tidak hanya terkait dengan aspek keuangan (financial), namun juga dapat dilihat dari aspek layanan (services).

William Pasmore memberikan definisi kinerja terbaik sebuah organisasi sebagai keberhasilan dalam menciptakan fleksibilitas, capaian yang tinggi, dan budaya organisasi pembelajar untuk mendapatkan keunggulan kompetitif di dunia yang tidak pernah diam [16]. Luftman dalam bukunya Managing the Information Technology Resource menyebutkan bahwa keuntungan kompetitif akan tumbuh dari kesiapan organisasi untuk meraih posisi superior terhadap pesaing-pesaingnya (biaya lebih rendah, kualitas lebih baik, produk/jasa terdepan) [17]. Lebih jauh ia menyampaikan bahwa Teknologi Informasi merupakan komponen yang sangat penting untuk mewujudkan kesuksesan suatu organisasi dan keberhasilan dalam manajemen sumber daya TI merupakan prasyarat untuk mencapai keunggulan kompetitif [17]. Sementara itu, Michael E Potter menyatakan bahwa kinerja terbaik tercapai jika organisasi dapat mencapai keuntungan kompetitif yang meliputi strategi untuk melanggengkan keuntungan biaya (cost leadership), diferensiasi produk (product differentiation), serta segmentasi pasar (segmentation) [18]. Lebih jauh Jessica Keyes menyampaikan bahwa untuk mencapai kinerja terbaik sesuai visi dan misi organisasi, maka diperlukan manajemen kinerja. Ia mengartikan manajemen kinerja sebagai upaya memanfaatkan informasi pengukuran kinerja (performance measurement) untuk memberikan perubahan positif pada budaya, sistem, dan proses organisasi [19]. Lau menyatakan bahwa keunggulan kompetitif ditunjukkan oleh adanya hasil kinerja terbaik dan keunggulan sumber daya produks [20]. Berdasarkan berbagai definisi tersebut dapat ditarik kesimpulan bahwa kinerja terbaik sebuah organisasi merupakan kualitas tertinggi dari sebuah kegiatan organisasi yang akan menghasilkan keunggulan kompetitif terhadap para pesaingnya. Kualitas terbaik tersebut dapat berupa profitabilitas, kepuasan pelanggan, ataupun ukuran-ukuran lain yang ditetapkan organisasi sesuai dengan visi, misi, serta lini bisnisnya.

Kesehatan organisasi (organization health) merupakan kemampuan organisasi untuk melakukan penyelarasan internal (internal alignment), mencapai kualitas pelaksanaan program (quality of execution), serta kapasitas untuk memperbarui diri (renewal capacity) secara lebih cepat daripada para kompetitornya [4]. Internal alignment diturunkan menjadi tiga elemen, yaitu: direction, leadership, dan culture and climate. Sementara itu kualitas pelaksanaan program diturunkan menjadi empat elemen, yaitu: accountability, coordination and control, capabilities, serta motivation. Sedangkan renewal capacity dibangun dari elemen external orientation dan innovation and learning. Deskripsi dari sembilan elemen tersebut adalah sebagai berikut: Direction, adalah tujuan/arah yang jelas untuk dicapai oleh sebuah organisasi dan akan memberikan arti penting bagi para anggotanya. Leadership, merupakan tingkat kemampuan yang dimiliki pemimpin untuk menginspirasi orang lain. Culture and Climate, merupakan keyakinan yang tertanam pada setiap anggota organisasi dan kualitas interaksi diantara unit yang ada dalam organisasi. Accountability, sejauh mana individu memahami apa yang diharapkan dari mereka, memiliki kewenangan yang cukup untuk melaksanakannya, dan mengambil tanggung jawab untuk memberikan hasil. Coordination and control, kemampuan untuk mengevaluasi kinerja dan resiko organisasi, mengatasi permasalahan yang timbul, serta mengambil kesempatan yang ada. Capabilities, tingkat keterampilan dan bakat institusional yang diperlukan untuk melaksanakan strategi dan menciptakan keunggulan kompetitif. Motivation, antusiasme yang mendorong seseorang untuk terlibat dalam upaya yang luar biasa demi tercapainya hasil yang diharapkan. External orientation, kualitas interaksi dengan para pemilik kepentingan (stakeholders). Innovation and learning, kualitas dan aliran ideide baru, serta kemampuan organisasi untuk 
beradaptasi dan menyesuaikan diri dengan kebutuhannya.

Konsep dasar dari keberlangsungan (sustainability) adalah pengawetan [12]. Hal ini didasarkan pada pendapat Luftman yang menyatakan bahwa sustainability adalah kemampuan untuk mempertahankan teknologi dalam jangka panjang [21]. Sejalan dengan hal tersebut, Braa, dkk mendefinisikan keberlangsungan sebagai aktivitas yang dilakukan untuk menjadikan sistem informasi bermanfaat dari waktu ke waktu [7]. Untuk dinyatakan sustainable sebuah sistem informasi tidak saja cukup untuk bisa diimplementasikan dan digunakan, namun harus dapat terus-menerus dimanfaatkan di masa yang akan datang [22]. Sehingga untuk mencapai keberlangsungan sistem informasi diperlukan aktivitas evaluasi, perbaikan sistem, peningkatan keahlian sumber daya manusia [23]. Sadler menyatakan bahwa sustainability tergantung tiga karakteristik sumberdaya dan kapabilitas, yaitu periode untuk mempertahankan (durability), transferability, serta replicability [24]. Jamhour menyimpulkan bahwa kemampuan untuk mempertahankan sistem informasi dalam jangka panjang ditentukan dua dimensi, yaitu flexibility dan responsiveness [25]. Sejalan dengan hal tersebut, Arie de Geus menyatakan bahwa untuk mencapai sustainability dibutuhkan beberapa persyaratan, yaitu: sensitif terhadap perubahan zaman, memiliki identitas/jati diri/nilainilai/budaya kerja yang kuat, serta adanya lingkungan kerja yang kondusif untuk inovasi [26].

DICE Framework merupakan alat yang dikembangkan sejak 1992 oleh Harold L Sirkin et.al. dan selesai pada tahun 1994. Sebelas tahun kemudian Boston Consulting Group (BCG) menggunakannya untuk untuk mengukur seberapa baik sebuah perusahaan mengimplementasikan inisiatif perubahan, atau seberapa baik akan mampu mengimplementasikan inisiatif perubahan tersebut [27]. Secara lebih sederhana Model DICE framework dapat digunakan untuk memprediksi tingkat keberhasilan sekaligus untuk mengetahui kekurangan yang ada dalam implementasi manajemen perubahan. DICE Framework terdiri dari empat elemen sebagai berikut [27]: D (Duration), merupakan jangka waktu penyelesaian program perubahan (short term project) atau jangka waktu antar pelaksanaan pengawasan (longterm project). Pelaksanaan review yang berkala dan jangka waktunya tidak lama akan memiliki resiko yang lebih kecil atau mempunyai tingkat keberhasilan yang lebih tinggi. I (Integrity), merupakan kemampuan dari tim proyek (skill, knowledge, networking, serta leadership) untuk dapat menyelesaikan program perubahan tepat pada waktunya. C (Commitment), merupakan komitmen dari Eksekutif/Senior Manajemen (C1) dan pegawai/karyawan/employee (C2). E (Effort), merupakan jumlah penambahan beban kerja yang diperlukan dibandingkan beban kerja yang sekarang. Semakin sedikit penambahan beban kerja semakin memberikan resiko yang kecil dan potensi keberhasilannya lebih besar.

Formula DICE framework adalah sebagai berikut:

$$
\text { DICE Score }=D+(2 x I)+(2 x C 1)+C 2+E
$$

Penilaian elemen-elemen DICE dilakukan dengan ketentuan sebagai berikut: Setiap elemen DICE tersebut diberikan penilaian dengan skala $1-4$. Semakin kecil skor yang diperoleh berarti menunjukkan semakin kecilnya resiko yang akan timbul dan semakin tinggi juga potensi keberhasilan suatu program. Kedua, hasil perhitungan dengan skor antara 7 dan 14 (7 < skor $\leq 14$ ) berarti bahwa proyek yang dilakukan cenderung berhasil yang disebut dengan Win Zone. Hasil perhitungan dengan skor lebih dari 14 namun kurang dari atau sama dengan 17 (14 < Skor $\leq 17)$ berarti bahwa risiko terhadap keberhasilan proyek meningkat yang disebut Worry Zone. Skor lebih dari 17 dan kurang dari $19(17<$ Skor $\leq 19)$ berarti bahwa proyek sangat berisiko. Skor lebih dari atau sama dengan 19 ( 19 < Skor) berarti bahwa proyek tidak mungkin berhasil yang disebut Woe Zone.

Berdasarkan tinjauan teoritis tersebut di atas, peneliti mencoba menyusun formula hipotesis sebagai berikut:

H1: Tidak semua elemen kesehatan organisasi berpengaruh signifikan terhadap keberlangsungan sistem informasi e-audit.

H2: Tidak semua elemen kesehatan organisasi berpengaruh signifikan terhadap kinerja sistem informasi e-audit.

H3: Organization health berpengaruh signifikan terhadap kinerja sistem informasi $e$-audit.

\section{Metode Penelitian}

Penelitian ini dilakukan dengan metode campuran (mix-methods) dengan strategi embedded concurrent. Metode campuran didefinisikan sebagai sebuah pendekatan untuk menyelidiki suatu objek dengan mengkombinasikan atau menghubungkan bentuk penelitian kualitatif dan kuantitatif [28]. Strategi embedded konkuren menerapkan satu tahap pengumpulan data kuantitatif dan kualitatif dalam satu waktu bersamaan. Selanjutnya pencampuran (mixing) data yang diperoleh dengan kedua metode tersebut dilakukan dalam pembahasan penelitian. Bentuk penggabungannya dapat dilakukan dengan 
melakukan komparasi ataupun melakukan deskripsi secara berdampingan. Metode ini juga menerapkan perspektif teoritis tertentu yang digunakan sebagai landasan metode primer [28]. Metode dan tahapan penelitian ini dapat dilihat pada Gambar 1 berikut:

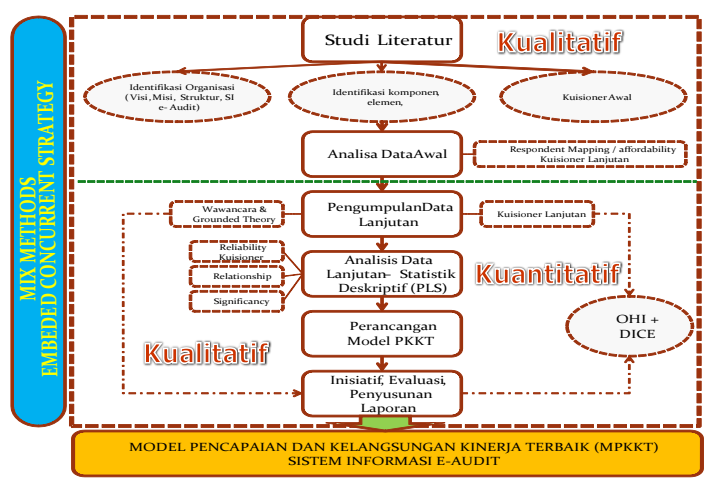

Gambar 1. Metode penelitian

Secara ringkas penelitian ini dibagi menjadi lima tahapan sebagai berikut: Pertama, Aspire, pada tahapan ini dilakukan pendalaman teori terkait dengan penelitian yang dilakukan dengan melakukan studi literatur dari jurnal, buku, dan artikel yang relevan dengan penelitian. Kedua, Assess, tahap ini dilakukan dengan menyusun kuesioner yang akan digunakan untuk mengukur tingkat kesehatan obyek penelitian dan mengukur relasi dan tingkat signifikansi masing-masing elemen yang telah diidentifikasi sebelumnya. Selain itu kuesioner juga digunakan untuk mengukur persepsi responden terhadap peluang keberhasilan sistem informasi $e$-audit dan menentukan tingkat resiko yang mungkin terjadi. Ketiga, Architect, tahap ini dilakukan dengan pengolahan data kuesioner untuk menguji relasi dan signifikansi elemen-elemen yang ada, sehingga dihasilkan model struktural keberhasilan dan keberlangsungankinerja terbaik SI e-audit. Selain itu juga diidentifikasi resiko yang mungkin timbul. Keempat, Action, tahap ini terdiri dari kegiatan identifikasi aspirasi yang dibangun oleh pemeriksa sebagai subyek dalam pelaksanaan sistem informasi e-audit. Selanjutnya dilakukan perumusan inisiatif yang diperlukan untuk menjamin bahwa sistem informasi e-audit akan mewujudkan dan menjaga keberlangsungan kinerja terbaik SI e-audit. Kelima, Advance, Tahap terakhir dari penelitian ini yaitu perumusan metode yang bertujuan untuk menjamin bahwa sistem informasi e-audit akan terus berjalan. Tahap ini sangat penting untuk menjamin bahwa perubahan yang dilakukan BPK RI tidak akan tertinggal oleh perubahan yang terjadi pada sistem informasi di entitas.
Sistem informasi ini akan digunakan oleh seluruh pemeriksa yang tersebar di seluruh Indonesia yang berjumlah 2.744 orang [29]. Sehingga penelitian akan menggunakan pendekatan kuantitatif dengan menyebarkan kuesioner ke para pemeriksa yang dipilih secara purposive sampling. Kuesioner yang disusun terdiri dari dua bagian, bagian pertama adalah data demografi responden dan bagian kedua adalah pertanyaan/pernyataan sesuai dengan variabel yang diukur. Kuesioner mengacu pada skala Likert 1-4, artinya jawaban responden diberi pembobotan skor 1 sampai dengan 4 dengan uraian sebagai berikut [30]: 1 (Sangat Tidak Setuju /STS), 2 (Tidak Setuju/TS), 3 (Setuju/S), 4 (Sangat Setuju/SS). Skala Likert 1- 4 tersebut menghilangkan opsi jawaban ragu-ragu. Hal ini bertujuan untuk menghindari jawaban yang bermakna ganda (multitafsir) dan tidak menjelaskan kecenderungan yang lebih dominan dari jawaban responden. Penyebaran kuesioner dilakukan secara langsung dalam bentuk hardcopy dan dengan cara online melalui social media (email, facebook). Kuesioner yang disebarkan sebanyak 190 buah, namun sampai dengan batas waktu yang ditentukan hanya 100 buah kuesioner yang dikembalikan dan memenuhi kriteria untuk dianalisis.

Sampel adalah bagian yang lebih kecil yang dipilih peneliti dari jumlah dan karakteristik yang dimiliki oleh populasi [31]. Metode pemilihan sampel yang digunakan peneliti adalah purposive sampling. Berdasarkan teknik ini, peneliti menentukan bahwa responden yang dipilih adalah para auditor baik yang ditempatkan di unit kerja teknis, unit kerja penunjang/pendukung, serta para pejabat struktural di lingkungan BPK RI. Hal ini dilakukan dengan pertimbangan bahwa merekalah yang akan menjadi subyek dari pelaksanaan sistem informasi e-Audit. Jumlah sampel untuk model komplek dengan 100 indikator dapat dianalisis hanya dengan jumlah sampel data 50 buah [32]. Namun demikian Slovin menentukan bahwa jumlah sampel dapat ditentukan dengan rumus sebagai berikut [33]:

$$
n=N /\left(1+N e^{2}\right)
$$

dimana,

$$
\begin{aligned}
& n=\text { jumlah sampel } \\
& N=\text { jumlah populasi } \\
& e=\% \text { kesalahan yang bisa ditolerir }
\end{aligned}
$$

Berdasarkan rumus tersebut dapat ditentukan jumlah sampel sebagai berikut:

$$
\begin{gathered}
n=2.744 /\left(1+2.744 \times 0,1^{2}\right) \\
n=96,48
\end{gathered}
$$


Jadi jumlah sampel dalam penelitian ini minimal adalah 96 orang responden.

Pengolahan data dipilih menggunakan software SmartPLS versi 2.0. SmartPLS ini merupakan jenis Structural Equation Modelling (SEM) dengan metode alternatif Partial Least Square (PLS) yang merupakan SEM berbasis variance (Component Based SEM). Berbeda dengan Covariance Based SEM (AMOS, LISREL) yang mengharuskan berbagai asumsi (data berdistribusi normal, pengukuran variabel continue, jumlah sampel besar) dipenuhi, SEMPLS mengabaikan berbagai asumsi tersebut karena bersifat non-parametrik [32]. Wold (1985) menyatakan bahwa PLS merupakan metode analisis yang powerful oleh karena tidak didasarkan banyak asumsi. Data tidak harus berdistribusi normal multivariate (indikator dengan skala kategori, ordinal, interval sampai rasio dapat digunakan pada model yang sama) dan sampel tidak harus besar [32]. Selain dapat digunakan untuk mengkonfirmasi teori, PLS juga dapat digunakan untuk menjelaskan ada atau tidaknya hubungan antar variabel laten. Fornell dan Bookstein (1982) menyebutkan bahwa dibandingkan dengan Covariance Based SEM, PLS akan menghindarkan dua masalah serius yaitu inadmisable solution dan factor indeterminacy [32]. Pengolahan data dengan SEM-PLS kemudian akan menghasilkan model hubungan antar variabel organization health pada sistem informasi e-audit. Model ini disebut dengan Model Keberhasilan dan Keberlangsungan Kinerja Terbaik (MK3T) Sistem Informasi.

Uji Validitas perlu dilakukan untuk mengetahui sejauh mana kuesioner dapat mengukur variabel penelitian. Ranjit Kumar (2005) menyatakan bahwa validitas merupakan kemampuan dari instrumen dalam kuesioner untuk dapat mengukur rancangan penelitian [34]. Suatu pertanyaan/pernyataan dalam kuesioner dinyatakan valid jika mampu mengungkapkan dengan jelas suatu hal yang akan diukur oleh kuesioner tersebut. Chin (1998) menyatakan bahwa suatu indikator dikatakan valid jika mempunyai loading factor $\geq 0,5$ [32]. Selain itu dilakukan uji reabilitas, yaitu untuk mengetahui tingkat konsistensi dan kestabilan kuesioner sehingga dapat menghasilkan prediksi secara akurat [34]. Dengan kata lain, uji reabilitas bertujuan untuk mengukur kestabilan dan konsistensi sebuah kuesioner dalam mengukur konsep atau konstruk. Metode SEM-PLS mengukur reabilitas dengan menghitung composite reliability dan Cronbach alpha masingmasing instrumen. Instrumen dikatakan reliabel bila memiliki nilai composite reliability $\geq 0,7$ dan Cronbach alpha $\geq 0,6$ [32].

\section{Hasil dan Pembahasan}

Sebagian besar responden berjenis kelamin perempuan yaitu sebesar $52 \%$ dan responden didominasi oleh pemeriksa yang berusia 30-40 tahun dengan jumlah 57\%. Mayoritas responden mempunyai latar belakang pendidikan sarjana (S1) dengan prosentase sebesar 65\%, responden didominasi oleh pegawai dengan masa kerja sampai dengan 10 tahun yaitu 70\%. Mayoritas responden mempunyai jabatan fungsional sebagai anggota tim dengan prosentase $63 \%$ dan mempunyai pengalaman melaksanakan tugas pemeriksaan lebih dari 10 kali yaitu mencapai $61 \%$ responden. Sebagian besar responden juga terbiasa menggunakan PC atau laptop dengan prosentase sebesar $71 \%$.

Evaluasi model pengukuran (outer model) berfungsi untuk mendefinisikan bagaimana setiap blok indikator berhubungan dengan variabel latennya. Terdapat tiga kriteria untuk menguji outer model, yaitu validitas konvergen (Convergent Validity), validitas diskriminan (Discriminant Validity) atau menggunakan rerata ekstraksi varian (Average Varian Extracted), dan construct reliability yang diukur menggunakan composite reliability dan croncbach alpha. Uji validitas konvergen dilakukan untuk menentukan apakah semua pertanyaan (instrument) dalam kuesioner penelitian yang digunakan untuk mengukur variabel penelitian adalah valid. Sebuah instrument penelitian akan dinyatakan valid jika nilai loading factor sama atau lebih besar dari 0,5. Discriminant validity dapat dihitung dengan membandingkan nilai akar kuadrat dari average variance extracted $(\sqrt{A V E})$ setiap konstruk dengan korelasi antara konstruk dengan konstruk lainnya dalam model. Model dinyatakan mempunyai discriminate validity yang cukup jika akar AVE untuk setiap konstruk lebih besar daripada korelasi antara konstruk dan konstruk lainnya dalam model [32].

Reabilitas konstruk diuji dengan dua kriteria, yaitu composite reliability dan cronbach alpha dari blok indikator yang mengukur konstruk. Konstruk dinyatakan reliable jika memiliki nilai composite reliability $\geq 0,7$ dan Cronbach alpha $\geq$ 0,6 [32]. Berdasarkan perhitungan diketahui bahwa instrumen yang digunakan untuk penelitian ini sudah memenuhi kriteria untuk dinyatakan reliable. Adapun ringkasan dari perhitungan construct reliability adalah sebagai berikut: 
84 Journal of Information Systems, Volume 8, Issue 2, October 2012

TABEL I

CONSTRUCT RELIABILITY

\begin{tabular}{ccc}
\hline Elemen & $\begin{array}{c}\text { Composite } \\
\text { Reliability }\end{array}$ & $\begin{array}{c}\text { Cronbachs } \\
\text { Alpha }\end{array}$ \\
\hline Direction & 0,9067 & 0,8857 \\
Leadership & 0,9387 & 0,9282 \\
Culture\&Climate & 0,9209 & 0,9079 \\
Accountability & 0,9133 & 0,8983 \\
Coordination\&Control & 0,8808 & 0,8605 \\
Capabilities & 0,8437 & 0,7867 \\
Motivation & 0,9038 & 0,8799 \\
External orientation & 0,8792 & 0,8476 \\
Inovation & 0,922 & 0,9086 \\
Healthy & 0,8919 & 0,8161 \\
Performance & 0,9072 & 0,8838 \\
Internal alignment & 1 & 1 \\
Quality execute & 1 & 1 \\
Renewing capacity & 1 & 1 \\
\hline
\end{tabular}

Pengujian model struktural (inner model) dilakukan untuk mengetahui hubungan diantara konstruk laten seperti dinyatakan dalam hipotesis yang telah disusun sebelumnya. Pengujian inner model ini dilakukan dengan dua kriteria, yaitu pengujian goodness-fit model dan uji signifikansi hubungan konstruk. Pengujian goodness-fit model dilakukan dengan melihat nilai $R$-Square. Konstruk dinyatakan dapat dijelaskan oleh konstruk lainnya jika nilai R-Square lebih besar dari 0,1 atau lebih besar dari 10\%. Hasil pengujian goodness-fit model dapat dilihat pada Tabel II berikut:

TABEL II UJI GOODNESS-FIT MODEL

\begin{tabular}{cc}
\hline Elemen & R-Square \\
\hline Direction & - \\
Leadership & - \\
Culture\&climate & - \\
Accountability & - \\
Coordination\&control & - \\
Capabilities & - \\
Motivation & - \\
External orientation & - \\
Inovation & - \\
Healthy & 1 \\
Performance & 0,4219 \\
Internal alignment & 0,2517 \\
Quality execute & 0,4133 \\
Renewing capacity & 0,4940 \\
\hline
\end{tabular}

Berdasarkan Tabel uji goodness-fit model tersebut diketahui bahwa variasi konstruk healthy dapat dijelaskan oleh konstruk internal alignment, quality of execution, serta renewing capacity sebesar 1 atau $100 \%$. Sementara itu variansi konstruk internal alignment dapat dijelaskan oleh konstruk direction, leadership, culture/climate sebesar $25,17 \%$, konstruk quality of execution dapat dijelaskan oleh konstruk accountability, coordination/control, capabilities, motivation, sebesar 41,33\%, serta konstruk renewing capacity dapat dijelaskan oleh konstruk external orientation dan innovation sebesar 49,4\%. Sementara itu konstruk performance yang memiliki $R$-Square sebesar 0,4219 berarti bahwa $42,19 \%$ variansi yang terjadi pada konstruk performance dapat dijelaskan oleh konstruk health, sedangkan $57,81 \%$ lainnya dijelaskan oleh variabel lain di luar model.

Pengujian inner model yang kedua adalah pengujian signifikansi pengaruh konstruk. Pengujian ini dilakukan dengan melihat nilai koefisien parameter (path coefisien) dan nilai signifikansi t statistik. Koefisien parameter akan menunjukkan pegaruh konstruk positif atau negatif, sedangkan pengaruh konstruk dinyatakan signifikan jika nilai t statistik lebih besar dari nilai $\mathrm{t}$ tabel (t tabel signifikansi 5\%=1,96) [32]. Hasil pengujian inner model dapat dilihat pada Tabel III berikut:

TABEL III PENGUJian INNER MODEL

\begin{tabular}{|c|c|c|}
\hline Hubungan antar Konstruk & $\begin{array}{c}\text { Path } \\
\text { Coefisien }\end{array}$ & $\begin{array}{c}t- \\
\text { statistics }\end{array}$ \\
\hline Direction -> Aligning & 0,0788 & 0,5827 \\
\hline Direction -> Sustain & 0,0297 & 0,589 \\
\hline Leadership -> Aligning & 0,2932 & 2,3833 \\
\hline Leadership -> Sustain & 0,1108 & 2,3455 \\
\hline Culture\&Climate -> Aligning & 0,217 & 2,0003 \\
\hline Culture\&Climate -> Sustain & 0,0819 & 1,9578 \\
\hline Aligning -> Sustain & 0,3777 & 15,0473 \\
\hline Accountability $->$ Execute & 0,0308 & 0,2699 \\
\hline $\begin{array}{l}\text { Accountability -> Sustain } \\
\text { Coordination \&Control -> }\end{array}$ & 0,0124 & 0,2622 \\
\hline $\begin{array}{c}\text { Execute } \\
\text { Coordination\&Control -> }\end{array}$ & 0,0168 & 0,0879 \\
\hline Sustain & 0,0068 & 0,0863 \\
\hline Capabilities -> Execute & 0,3346 & 2,3639 \\
\hline Capabilities -> Sustain & 0,1348 & 2,3773 \\
\hline Motivation -> Execute & 0,3507 & 2,2179 \\
\hline Motivation -> Sustain & 0,1412 & 2,1696 \\
\hline $\begin{array}{c}\text { Execute -> Sustain } \\
\text { External Orientation -> }\end{array}$ & 0,4027 & 11,8924 \\
\hline Renewing & 0,27 & 1,7476 \\
\hline $\begin{array}{l}\text { External Orientation -> Sustain } \\
\quad \text { Innovation\&Learning -> }\end{array}$ & 0,1049 & 1,7593 \\
\hline $\begin{array}{c}\text { Renewing } \\
\text { Innovation\&Learning -> }\end{array}$ & 0,4815 & 3,0987 \\
\hline Sustain & 0,1871 & 2,9507 \\
\hline Renewing -> Sustain & 0,3885 & 14,1292 \\
\hline
\end{tabular}

Pengujian hipotesis pada penelitian ini dilakukan dengan menggunakan nilai path coefisien dan $t$ statistik dari output Smart PLS 2.0 yang dibandingkan dengan nilai $t$ tabel dengan tingkat signifikansi $95 \%$ atau $\alpha=0,05$ yaitu sebesar 1,96. 
H1: Tidak semua elemen Organization Health berpengaruh signifikan terhadap keberlangsungan sistem informasi $e$ audit

Hasil pengujian hipotesis sebagaimana disajikan dalam Tabel III menunjukkan bahwa nilai $t$-statistik untuk setiap elemen organization health tidak semuanya bernilai di atas 1,96. Terdapat empat elemen yang secara langsung mempunyai pengaruh signifikan terhadap keberlangsungan sistem informasi $e$-audit, yaitu: leadership, capabilities, motivation, serta innovation and learning. Disamping berpengaruh langsung terhadap sustainability, keempat elemen tersebut juga mempunyai pengaruh signifikan terhadap keselarasan internal, kualitas proses, serta kemampuan untuk memperbarui diri. Leadership dan culture \& climate berpengaruh signifikan terhadap internal alignment dengan nilai $t$-statistik masing-masing adalah 2,3833 dan 2,0003. Capabilities dan motivation berpengaruh signifikan dalam menentukan quality of execution, yaitu dengan nilai $t$-statistik 2,3639 dan 2,2179. Sementara innovation \& learning mempunyai nilai $t$-statistik sebesar 3,0987 yang berarti mempunyai pengaruh signifikan terhadap renewing capacity. Sementara itu terdapat empat elemen yang tidak mempunyai pengaruh signifikan baik secara langsung terhadap keberlangsungan sistem informasi $e$-audit maupun terhadap internal alignment, quality of execution, dan renewing capacity. Keempat elemen tersebut adalah direction, accountability, coordination and control serta external orientation. Masing-masing elemen tersebut mempunyai nilai $t$-statistik lebih kecil dari 1,96. Sementara itu elemen culture and climate yang dalam hubungannya dengan keberlangsungan sistem informasi e-audit mempunyai nilai $t$-statistik 1,9576 berarti tidak mempunyai hubungan signifikan, namun demikian elemen culture and climate ini signifikan dalam menentukan tercapainya keselarasan internal dengan nilai $t$-statistik 2,0003. Oleh sebab itu dapat dinyatakan bahwa hipotesis pertama $(\mathrm{H} 1)$ diterima.

\section{H2: Tidak semua elemen Organization Health berpengaruh signifikan terhadap kinerja Sistem Informasi $e$-audit}

Hasil pengujian terhadap inner model elemen organization health menunjukkan data sebagai berikut:
TABEL IV

PENGUJian INNER ModeL

\begin{tabular}{ccc}
\hline Hubungan antar Konstruk & $\begin{array}{c}\text { Path } \\
\text { Coefisien }\end{array}$ & $\begin{array}{c}\boldsymbol{t} \text { - } \\
\text { statistics }\end{array}$ \\
\hline Direction -> Performance & 0,0195 & 0,5428 \\
Leadership -> Performance & 0,0725 & 2,3597 \\
Culture\&Climate -> Performance & 0,0536 & 1,8736 \\
Aligning -> Performance & 0,2472 & 8,8213 \\
Accountability -> Performance & 0,0081 & 0,2622 \\
Coordination\&Control -> & 0,0044 & 0,0852 \\
Capabilities -> Performance & 0,0882 & 2,1526 \\
Motivation -> Performance & 0,0924 & 2,0925 \\
Execute -> Performance & 0,2636 & 9,0738 \\
External Orientation -> & 0,0686 & 1,5199 \\
Innovation \&Learning -> & 0,1224 & 2,8848 \\
Renewing -> Performance & 0,2543 & 6,861 \\
Sustain -> Performance & 0,6544 & 7,6307 \\
\hline
\end{tabular}

Berdasarkan hasil perhitungan path coefisien dan $t$-statistik tersebut dapat diketahui bahwa terdapat empat elemen organization health yang mempunyai hubungan positif dan signifikan dalam menentukan kinerja sistem informasi $e$-audit. Keempat elemen tersebut adalah leadership, capabilities, motivation, serta innovation and learning. Keempat elemen tersebut mempunyai nilai path coefisien positif dan nilai $t$-statistik masing-masing 2.3597, 2.1526, 2.0925, serta 2.8848. Sejalan dengan keempat elemen tersebut, kinerja sistem informasi e-audit dipengaruhi oleh keselarasan internal, kualitas pelaksanaan program, serta kemampuan untuk memperbarui diri. Sementara Tabel IV tersebut juga mengkonfirmasi bahwa lima elemen organization health, yaitu direction, culture and climate, accountability, coordination and control, serta external orientation tidak mempunyai pengaruh langsung yang signifikan terhadap kinerja sistem informasi e-audit. Kelima elemen tersebut mempunyai nilai path coefisien positif yang artinya mempunyai pengaruh positif, namun nilai $t$-statistiknya berada di bawah 1,96 . Nilai $t$-statistik dari masing-masing elemen tersebut adalah $0.5428,1.8736,0.2622,0.0852$, serta 1.5199 . Hal ini berarti bahwa kelima elemen tersebut tidak mempunyai hubungan yang signifikan dalam menentukan kinerja sistem informasi $e$-audit. Berdasarkan uraian tersebut di atas dapat dinyatakan bahwa hipotesis kedua (H2) yang menyebutkan tidak semua elemen organization health berpengaruh signifikan terhadap kinerja sistem informasi e-audit diterima.
H3: Organization Health berpengaruh signifikan terhadap kinerja Sistem Informasi $e$-audit


Tabel IV menunjukkan bahwa konstruk health dalam hubungannya dengan konstruk performance mempunyai nilai path coefficient 0,6628 dan nilai $t$-statistik 7,9313. Hal ini menunjukkan bahwa kualitas kesehatan organisasi mempunyai pengaruh yang signifikan terhadap kinerja sistem informasi $e$-audit di BPK RI. Oleh sebab itu dapat disimpulkan bahwa hipotesis kedua (H2) diterima.

Analisis keberhasilan sistem informasi $e$ audit dilakukan dengan menggunakan DICE framework. Berdasarkan hasil kuesioner yang disebarkan terhadap 100 responden yang merupakan pemeriksa di lingkungan BPK RI diperoleh data sebagai berikut: Pertama, D (Duration), sistem informasi $e$-audit direncanakan untuk berjalan dalam jangka waktu yang panjang. $19 \%$ responden menyatakan tidak setuju bahwa mekanisme review atas pelaksanaan sistem informasi ini akan dilaksanakan secara berkala (semesteran/tahunan). Berdasarkan data tersebut duration dinilai dengan skor 2. Kedua, I (Integrity), 50\% responden menyatakan tidak yakin bahwa mereka mempunyai kompetensi yang cukup untuk melaksanakan sistem informasi $e$ audit. Hal tersebut menunjukkan bahwa terdapat potensi resistansi yang cukup besar, sehingga integrity dinilai dengan skor 3. Ketiga, C (Commitment), 91\% responden meyakini bahwa jajaran pimpinan di BPK RI mempunyai komitmen yang besar untuk pelaksanaan sistem informasi ini, sehingga untuk $\mathrm{C} 1$ dinilai dengan skor 1. Sementara itu $20 \%$ responden menyatakan bahwa komitmen staff pemeriksa tidak cukup besar dalam mendukung pelaksanaan sistem informasi e-audit, sehingga untuk $\mathrm{C} 2$ dinilai dengan skor 2. Keempat, E (Effort), 55\% responden menunjukkan kekhawatiran bahwa sistem informasi $e$-audit justru akan menambah beban dan waktu kerja mereka. Hal ini menunjukkan besarnya potensi resistansi yang akan timbul. Berdasarkan hal tersebut effort dinilai dengan skor 4.

Perhitungan nilai prediksi DICE dapat dihitung sebagai berikut:

$$
\begin{aligned}
\text { DICE Score }= & D+(2 \times I)+(2 \times C 1)+C 2+E \\
& =2+(2 \times 3)+(2 \times 1)+2+4 \\
& =\mathbf{1 6}
\end{aligned}
$$

Sebagaimana dinyatakan di atas bahwa hasil perhitungan dengan skor lebih dari 14 namun kurang dari atau sama dengan $17(14<$ Skor $\leq 17)$ berarti bahwa risiko terhadap keberhasilan sebuah program meningkat yang disebut Worry Zone.

Berdasarkan hasil pengolahan data statistik pada tahap sebelumnya kemudian ditentukan elemen apa saja yang mempunyai pengaruh positif dan signifikan terhadap keberhasilan dan keberlangsungan kinerja terbaik sistem informasi e-audit. Hasil rancangan MK3T sistem informasi $e$-audit dapat digambarkan sebagai berikut:

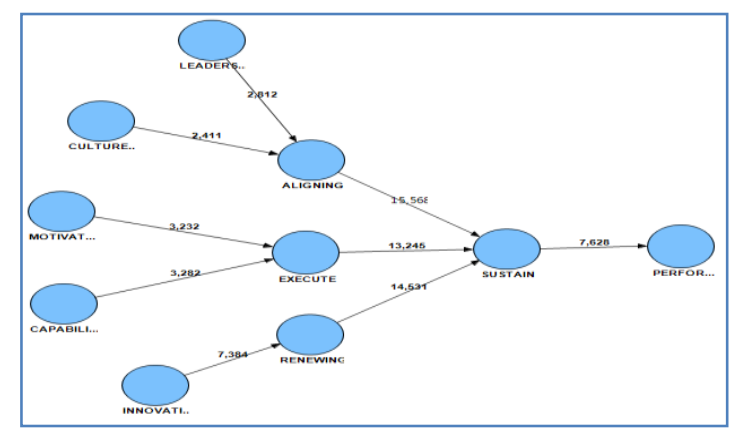

Gambar 2. MK3T SI e-Audit

Berdasarkan model yang diusulkan di atas selajutnya dilakukan penilaian terhadap tingkat kesehatan organisasi. Scott Keller menyatakan bahwa terdapat tiga tingkatan kesehatan, yaitu sakit (ailing), sehat (able), sangat sehat (elite). Terdapat dua syarat bagi sebuah organisasi untuk mencapai level able. Pertama, organisasi tersebut harus mencapai nilai di atas kuartil terbawah (to be above the bottom quartile) untuk seluruh 37 praktek. Kedua, minimal terdapat 6 hingga 10 praktek yang memperoleh nilai kuartil teratas. Tabel V menunjukkan hasil penilaian atas 37 praktek yang ada:

TABEL V

HASIL PENILAIAN ELEMEN MK3T

\begin{tabular}{lcc}
\multicolumn{1}{c}{ Praktek } & Skor Health & Elemen \\
\hline Meaningful Values & 3,11 & Motivation \\
Capturing External Ideas & 3,07 & Innovation \\
Operationally Diciplined & 3,06 & Culture \\
Creative and enterpreneurial & 3,05 & Culture \\
Process-based capabilities & 3,02 & Capabilities \\
Open \& trusting & 3,01 & Culture \\
Bottom-up innovation & 3,00 & Innovation \\
Top-down innovation & 2,98 & Innovation \\
Outsources expertise & 2,98 & Capabilities \\
Talent Development & 2,97 & Capabilities \\
Consultative leadership & 2,92 & Leadership \\
Authoritative leadership & 2,91 & Leadership \\
Inspirational Leaders & 2,90 & Motivation \\
Supportive leadership & 2,90 & Leadership \\
Challenging leadership & 2,89 & Leadership \\
Knowledge Sharing & 2,88 & Innovation \\
Internally competitive & 2,83 & Culture \\
Talent acquisition & 2,73 & Capabilities \\
Career Opportunities & 2,71 & Motivation \\
Rewards and Recognition & 2,57 & Motivation \\
Financial Incentives & 2,45 & Motivation \\
\hline
\end{tabular}

Tabel $\mathrm{V}$ di atas menunjukkan bahwa terdapat enam praktek dari empat elemen yang berada pada kuartil teratas. Keenam praktek tersebut 
adalah meaning values (motivation), capturing external idea (innovation), operationally diciplined, creative and enterpreneural, open and trusting (culture and climate), serta process based capabilities (capabilities). Berdasarkan uraian tersebut di atas dapat dinyatakan bahwa kondisi organisasi berada pada posisi sehat. Namun demikian level kesehatan tersebut berada pada tingkat minimal karena hanya 6 dari 21 praktek yang mempunyai nilai yang masuk dalam kuartil teratas. Sehingga masih terdapat 15 praktek yang perlu mendapat perhatian untuk diperbaiki.

Untuk mencapai level elit untuk setiap elemen, maka diperlukan berbagai inisiatif perbaikan. Inisiatif-inisiatif tersebut dapat dilihat pada Tabel VI berikut:

TABEL VI

INISIATIF PERBAIKAN

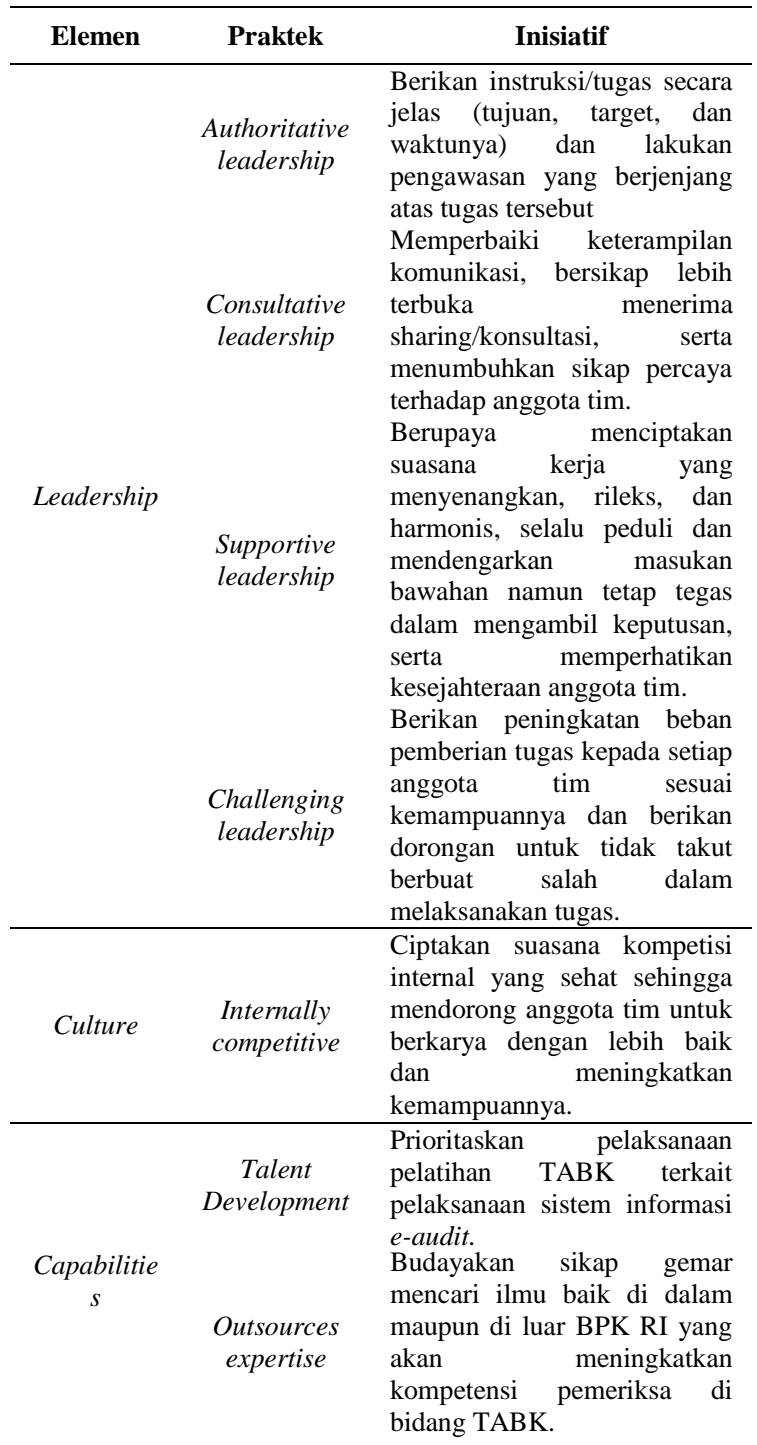

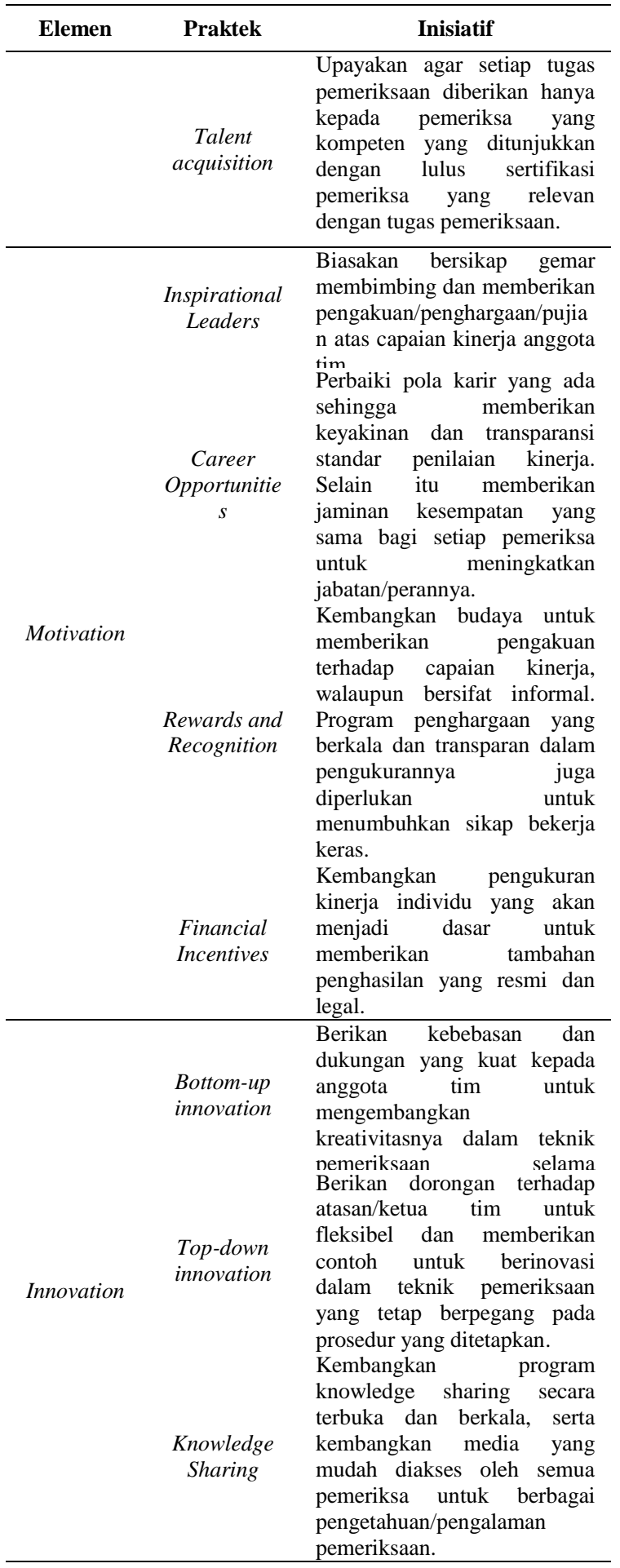

\section{Kesimpulan}

Berdasarkan hasil pembahasan pada bab-bab sebelumnya tentang model keberhasilan dan keberlangsungan kinerja terbaik sistem informasi 
e-audit pada BPK RI, maka dirumuskan kesimpulan sebagai berikut: Pertama, penelitian ini menghasilkan model struktural keberhasilan dan keberlangsungan kinerja terbaik sistem informasi $e$-audit di BPK RI. Berdasarkan pengolahan data kuesioner yang telah diperoleh kesimpulan bahwa terdapat lima elemen yang mempunyai pengaruh signifikan terhadap keberhasilan dan keberlangsungan kinerja terbaik sistem informasi $e$-audit. Kelima elemen tersebut adalah leadership, culture and climate, capabilities, motivation serta innovation and learning. Sementara itu juga diketahui bahwa pelaksanaan sistem informasi $e$-audit berada pada worry zone, artinya bahwa terdapat resiko kegagalan yang cukup signifikan. Resiko tersebut disebabkan oleh adanya potensi resistansi para pemeriksa akibat ketidakyakinan terkait dengan kompetensinya untuk melaksanakan sistem tersebut dan adanya anggapan bahwa sistem tersebut justru akan menambah beban kerja mereka. Kedua, hasil pengujian Model Keberhasilan dan Keberlangsungan Kinerja Terbaik (MK3T) Sistem Informasi menunjukkan bahwa organisasi BPK RI berada pada kondisi sehat namun pada level terendah. Hal ini diketahui karena hanya terdapat 6 praktek yang memperoleh penilaian "elite" dari 21 praktek yang berpengaruh signifikan terhadap keberhasilan dan keberlangsungan kinerja terbaik sistem informasi e-audit. Sementara terdapat 15 praktek lainnya memerlukan perhatian yaitu: Leadership (authoritative leadership, consultative leadership, supportive leadership, challenging leadership), Culture and climate (internally competitive), Capabilities (talent development, outsources expertise, talent acquisition), Motivation (inspirational leaders, career opportunities, rewards and recognition, financial incentives), serta Innovation and learning (bottom-up innovation, top-down innovation, knowledge sharing).

Pengembangan MK3T merupakan model generik untuk keberhasilan dan keberlangsungan kinerja terbaik sistem informasi $e$-audit di BPK RI. Penerapan model pada organisasi lain dapat menyertakan karakteristik spesifik dari obyek yang diteliti dan menyesuaikan dengan aspirasi yang diusung, yaitu: leadership driven, execution edge, costumer focus, atau knowledge core. Penelitian selanjutnya dapat mengeksplorasi elemen-elemen lain yang dapat memperkuat internal alignment, quality of execution, serta capacity for renewal selain dari kesembilan elemen tersebut. Selain itu, dapat juga dilakukan integrasi MK3T dengan model lain yang relevan

\section{Referensi}

[1] LSI, Lembaga Survey Indonesia., "Rilis LSI Korupsi: Persepsi Pemberantasan Korupsi." http://www.lsi.or.id. [Online] Januari 8, 2012. [Cited: 0301 Jam 20.00 WIB, 2012.]

[2] BPK RI., Rencana Strategis BPK RI 20112015. Jakarta : s.n., 2011.

[3] Palmer, Ian and dkk., Managing Organizational Change. Second. New York: McGraw-Hill, 2009.

[4] Keller, Scott and Price, Collin., Beyond Performance: How Great Organizations Build Ultimate Competitive Advantage. New Jersey: John Wiley \& Sons Ltd, 2011. pp. 22-23, 5.

[5] Ward, John and Peppard, Joe., Strategic Planning for Information System. 3rd. West Sussex : John Wiley and Sons Ltd, 2002. p. 23.

[6] Kettinger, William J and et., all., "Strategic Information System Revisited: A Study in Sustainability and Performance." March 1994, p. 31.

[7] Braa, J, Monteiro, E and Sahay, S., "Network of Action: Sustainability Health Information Systems Across Developing Countries." 2004, Vol. 28 (3), pp. 337-362.

[8] Avgerou, C., "IT and Organizational Change: an Institutionalist Perpsketive." Information Technology and People, 2000, Vol. 13 (4), pp. 234-262.

[9] Zhang, L, et al., "Critical Success Factors of Enterprise Resource Planning Systems Implementation Success in China." 2003. The 36th Hawaii International Conference on System Sciences. p. 10.

[10] Chatterjee, D, Grewal, R and Sambamurthy, V., "Shaping up for E-commerce: Institutional Enablers of the Organizational Assimilation of Web Technologies." MIS Quarterly. 26(2), 2002, pp. 65-89.

[11] Nah, F and Delgado, s., "Critical Success Factors for Enterprise Resource Planning Implementation and Upgrade." Journal of Computer Information System, 2006, pp. 99113.

[12] Nurdin, N, Stockdale, Rosemary and Scheepers, Helana., "Internal organization factors influencing sustainable implementation of information system: Experiences from local government in Indonesia." Geelong: s.n., 2012. Australasian Conference on Information System.

[13] Turban, Efraim et al., Information Technology for Management: Transforming 
Organization in The Digital Economy. s.l. : John Wiley \& Sons, Inc, 2007. ISBN 978-0470-04160-4.

[14] Wheelen, T.L and Hunger, D.J., Strategic Management and Business Policy. 8. New Jersey : Prentice Hall, 2002.

[15] Armstrong, M., "Performance Management: Key Strategies and Practical Guidelines." 3. 2006, p. Kogan.

[16] Pasmore, William., Creating Strategic Change: Designing the Flexible, High Performing Work Organization. New York: Wiley, 1994.

[17] Luftman, Jerry N., Managing the Information Technology Resource - Leadership in The Information Age. First. s.l. : Prentice Hall, 2003. p. 2. 0130351261.

[18] Porter, Michael E., Competitive Advantage: Creating and Sustaining Superior Performance. First. New York : Free Press, 1998.

[19] Keyes, Jessica., Aligning IT with Corporate Strategy : Implementing The IT alance Scorecard . Boca Raton: Auerbach Publication, 2005.

[20] Lau, Ronald S., "Competitive Factors and Their Relative Importance in The U.S. Electronic and Computer Industries." s.l. : International Journal of Operations and Production Management, 2002, Vol. 22 (1), pp. 125-135.

[21] Luftman, J and Brier, T., "Achieving and Sustaining Business-IT Alignment." California Management Review. 1999.

[22] Krisnha, S and Walsham, G., "Implementing public information system in developing countries: Learning from a success story." Information Technology for Development, s.1. : Taylor \& Francis, Ltd, 2005.

[23] Markus, M.L and Tanis, C., "The enterprise system experience-from adoption to success In R.W.Zmud (ed), Framing the domains of IT management: Projecting the future throught the past." [book auth.] R.W.Zmud. Framing the domains of IT management: Projecting the future throught the past. Cincinnati : Pinnaflex Educational Resources, Inc, 2000, pp. 173-207.

[24] Sadler, P., "Strategic Management." Second. s.l. : Kogan Page Limited, 2003.

[25] Jamhour Manar, Laith Alrubaiee, Sabah agha., "Effect of Core Competence on Competitive Advantage and Organizational Performance." s.l. : International journal of Business and Mangement, 2012, Issue Januari 2012, Vol. 7 No.1.

[26] Geus, Arie de., The Living Company. USA : Longview Publishing, 1997. ISBN 0-87584782-X.

[27] Sirkin, Harold L, Keenan, Perry and Jackson, Alan., "The Hard Side of Change Management." Oktober 2005, pp. 100-116.

[28] Creswell, John W., Research Design, Qualitative, Quantitative, And Mixed Methods Approach. 3rd Edition. Thousand Oaks California: SAGE Publication, 2010. ISBN: 0-7619-0070-5.

[29] BPK-RI., Statistik Pegawai BPK RI Per 31 Desember 2012. s.l. : Biro SDM, BPK RI, 2013.

[30] Kriyantono, Rachmat., Teknik Praktis Riset Komunikasi, disertai contoh praktis riset media, public relations, advertising, komunikasi organisasi,komunikasi pemasaran. Jakarta : Kencana, 2008.

[31] Neuman, W Lawrence., Social Research Methods: Qualitative and Quantitative Approach. 6th. Boston: Pearson Education Inc, 2006. p. 224.

[32] Ghozali, Imam., Structural Equation Modelling metode alternatif dengan Partial Least Square. Semarang: Badan Penerbit UNDIP, 2011. Vol. Edisi 3. ISBN 979.704.300.2.

[33] Setiawan, Nugraha., Penentuan Ukuran Sampel Memakai Rumus Slovin dan Tabel Krejcie-Morgan, Telaah Konsep dan Aplikasinya. Diskusi Ilmiah Jurusan Sosial Ekonomi Fakultas Peternakan Unpad: s.n., November 22, 2007.

[34] Kumar, Ranjit., Research Methodology: A step by step guide for beginners. Second. London: SAGE Publication Ltd, 2005. p. 153.

[35] Keller, Scott and Price, Collin., "Organization Health: The Ultimate Competitive Advantage." Juni, 2011, McKinsey Quarterly. 